\title{
HAZARD PERCEPTION TEST (HPT): A PILOT STUDY IN BRAZIL
}

\author{
Egas Caparelli-Daquer $^{1}$, Tais Santana ${ }^{1}$, Sheila Cordazzo ${ }^{2}$, Heloisa Alves ${ }^{1,3} \&$ Charles T. Scialfa ${ }^{2}$ \\ ${ }^{1}$ Rio de Janeiro State University (UERJ) \\ Rio de Janeiro, RJ, Brazil \\ Email: egas@uerj.br; taa_ss@hotmail.com \\ ${ }^{2}$ University of Calgary \\ Calgary, Alberta, Canada \\ Email: chipscialfa@gmail.com; scheilacordazzo@hotmail.com \\ ${ }^{3}$ Pontifícia Universidade Católica do Rio de Janeiro (PUC-Rio) \\ Rio de Janeiro, RJ, Brazil \\ Email: heloisaveiga@gmail.com
}

\begin{abstract}
Summary: Traffic collisions are a major cause of violent death and disability worldwide (Goldman \& Ausiello, 2009). In developing countries, mortality rates are significantly higher when compared to other countries. In Brazil, official data show 23.4 fatalities per 100,000 inhabitants, compared to 10.6 in the United States and 6.0 in Canada (Global Status Report on Road Safety, 2015). Driving requires specific motor and cognitive skills, such hazard perception. The Hazard Perception Test (HPT) assesses a drivers' ability to identify or anticipate dangerous situations in traffic (Horswill \& McKenna, 2004) and taps into different cognitive processes, such as speed to detect the hazard, judgment of hazard severity, and decision-making. The HPT has been directly associated with the risk of collision (Darby et al, 2009; McKenna \& Horswill, 1999; Quimby et al, 1986; Wells et al, 2008). Many countries, such as Australia and Great Britain, have made hazard perception a regular component of the driving test. In Brazil, however, candidates undergo an exam that has the characteristics of a clinical screening and does not assess context-specific cognitive abilities. Thus, there is a clear demand for clinical procedures with greater diagnostic sensitivity that address fundamental abilities such as hazard perception. The goal of the study was to employ an adapted version of the static Hazard Perception Test (s-HPT) under standardized Brazilian conditions. Results indicated that drivers' ability to perceive hazards is clearly dependent on variables such as expertise, age, and gender. The results are in accordance with previous studies conducted in other countries.
\end{abstract}

\section{OBJECTIVES}

The goal of the study was to employ an adapted version of the Hazard Perception Test (s-HPT) developed by Scialfa and collaborators (2012) to verify whether results obtained from a Brazilian sample follow the trends reported in the traffic safety literature. 


\section{METHODS}

\section{Participants}

A mixed-gender sample of 314 individuals was recruited among the candidates applying for or renewing their driver's license in the Division of Medicine and Psychology at the Department of Motor Vehicles of Rio de Janeiro (DETRAN-RJ). To be included in the study, participants had to be between 18 and 85 years of age and approved for license acquisition/renewal. Both amateur and professional drivers were included in the study. Drivers with disabilities and those who failed the license acquisition/renewal process were excluded. Table 1 presents the sample's demographic information.

Table 1. Sample demographic information

\begin{tabular}{ccccc}
\hline Gender & $\mathrm{N}$ & Age & Professional & $\begin{array}{c}\text { Non- } \\
\text { professional }\end{array}$ \\
\hline Male & 175 & $47.94(18.54)$ & $\mathrm{N}=72$ & $\mathrm{~N}=103$ \\
\hline Female & 139 & $50.10(18.02)$ & $\mathrm{N}=22$ & $\mathrm{~N}=117$ \\
\hline
\end{tabular}

\section{Materials}

Twenty one still images, from previous work (Scialfa et al, 2012), were selected to be the stimuli in this study. From those 21 scenes, two were eliminated from the set, with the criteria that those images were not found in the Brazilian driving environment (e.g., snow on the road and a traffic sign that is not used in Brazil). Another two images that contained no potential traffic conflicts were included in the series to modulate the observer's criterion for making a response. To evaluate if the set of scenes were in accordance with the Brazilian context, they were submitted to the judgment of four experts in traffic safety in Brazil. All four agreed that each of the images represented scenes found in Brazilian driving environments.

Potential traffic conflicts were defined as situations in which a collision (or near collision) between the driver and another road user would occur, or had the potential to occur, unless the driver took evasive action such as slowing, stopping, or steering. Each image was presented for four seconds. A 17-inch touch-sensitive LCD monitor (ELO touchscreen 1729L), with a resolution of $1280 \times 1024$ and connected to a laptop, was used to display the stimuli and collect responses. The software registered the spatial location and speed of every response during the test. If any response was within the areas defining a traffic conflict, then a response time was calculated. An example of a photographic image used in the study is shown in Figure 1. 


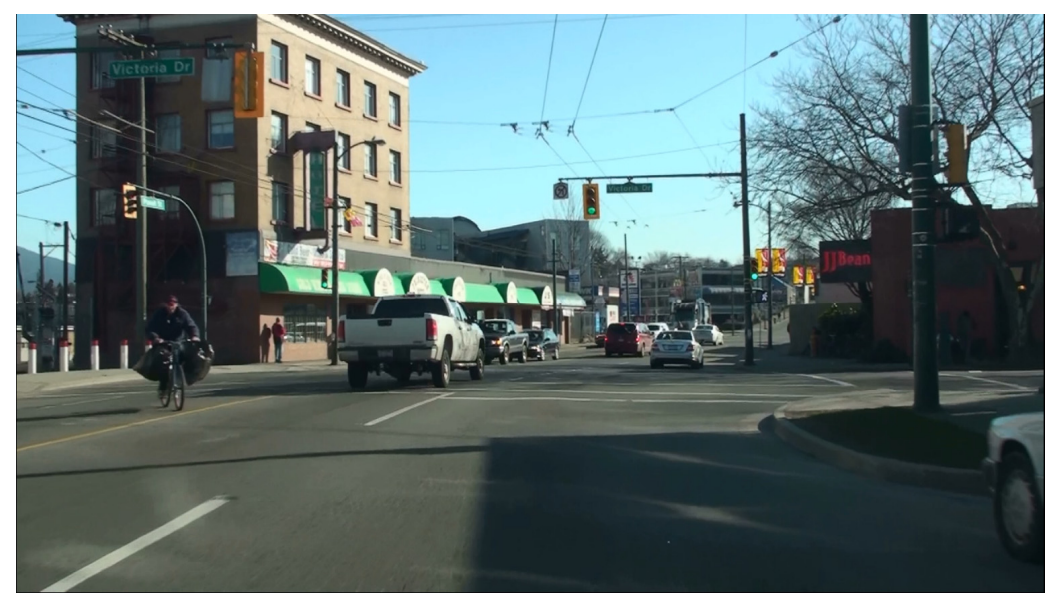

Figure 1. Example of a scene with traffic conflict: cyclist coming toward on a diagonal path

\section{Procedures}

Participants were tested in a single session lasting approximately 15 minutes. Upon arrival the participant read and signed a written informed consent document, and a demographics questionnaire was completed. Then, the participant received detailed instructions for the HPT and completed a simple touchscreen practice task in which they had to touch 12 randomly placed, numbered dots in numerical order. Next, the participant completed a simple reaction time task, where he/she was required to touch, as quickly as possible, squares that appeared randomly on the screen. Immediately after, 5 practice images were shown to familiarize the participant with the experiment. They were told:

"You will be shown images of traffic situations from a driver's point of view. We want you to watch the images as if you are the driver. While watching the images, your task is to ANTICIPATE potential traffic conflicts BEFORE they occur. A traffic conflict is a situation in which a collision (or near collision) between you and another road user would occur unless you took evasive action (such as slowing or steering). Your job is to touch any road user (or users) that could be involved in a POTENTIAL traffic conflict with your vehicle. In this task, 'road users' include moving vehicles, stationary vehicles, cyclists and pedestrians."

Throughout the practice block, feedback was provided to the participant. Once it was completed, the 21 test images were presented in a randomized order. At the end of the test block, the participant received feedback on his/her performance (percentage of correct responses). Different measures were calculated:

- Reaction Time $=$ mean reaction time for all trials, including false alarms

- Hits = number of responses to hazards in "hazard present" trials

- $\quad$ Errors = number of responses to non-hazards in "hazard present" trials

For the statistical analyses, participants were divided into different groups according to gender (male $\mathrm{x}$ female), expertise level (professional x non-professional), and age (group $1=19-34$ years; group $2=35-49$ years; group $3=50-64$ years; and group $4=65-86$ years of age). 


\section{RESULTS}

A preliminary multivariate analysis of variance (MANOVA) was conducted to examine the association between age, gender, and expertise level (as independent variables) and hits, reaction time, and errors (as dependent variables). The multivariate result was significant for gender [F $(3,297)=2.72, \mathrm{p}<0.045$, Wilks' $\Lambda=0.973$, partial $\left.\eta^{2}=0.027\right]$ and expertise level $[\mathrm{F}(3,297)=$ $6.95, \mathrm{p}<0.001$, Wilks' $\Lambda=0.934$, partial $\eta^{2}=0.066$ ]. Follow-up univariate analyses were then performed. The $\mathrm{F}$ tests showed there was a significant difference between males and females for reaction time $[\mathrm{F}=7.91$, $\mathrm{df}=(1,299), \mathrm{p}=0.005]$, and that professional and non-professional drivers differed with respect to reaction time $[\mathrm{F}=13.06, \mathrm{df}=(1,299), \mathrm{p}<0.001]$, hits $[\mathrm{F}=4.41$, $\mathrm{df}=(1,299), \mathrm{p}=0.037]$, and errors $[\mathrm{F}=10.18, \mathrm{df}=(1,299), \mathrm{p}=0.002]$. Results are shown in Figures 2-5.

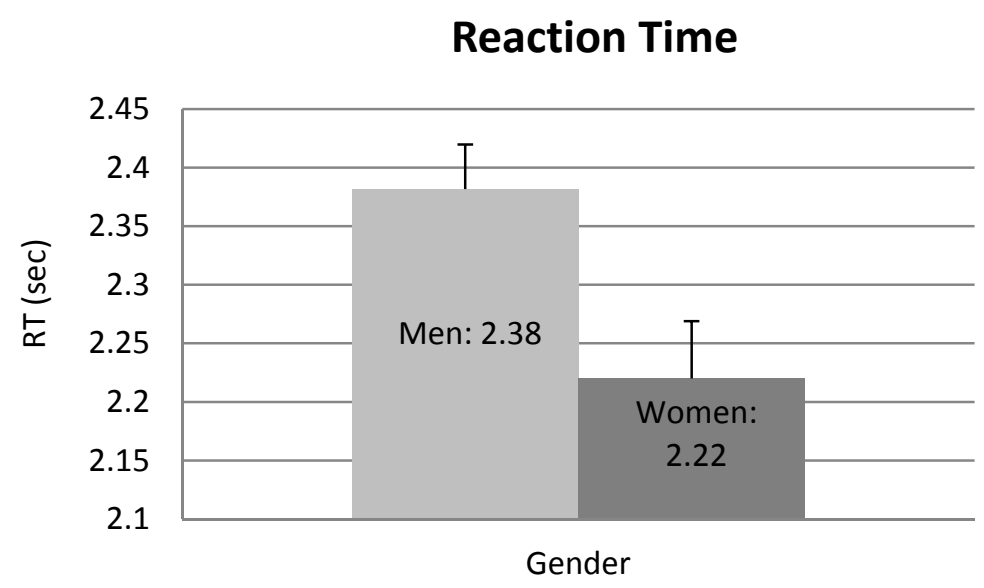

Figure 2. Difference in Reaction Time (sec) between male and female participants. Error bars represent 1 standard error

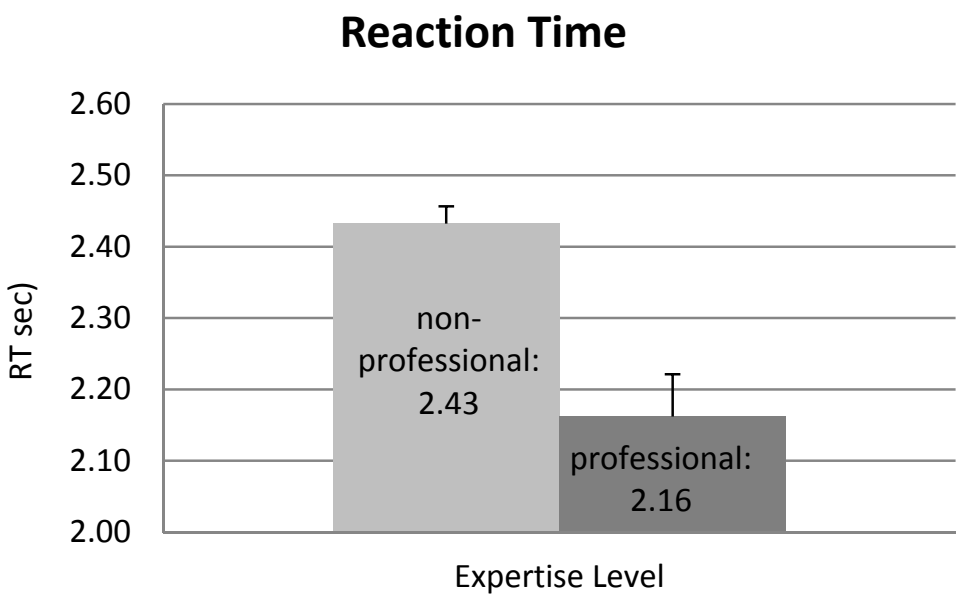

Figure 3. Difference between professional and non-professional drivers in Reaction Time. Error bars represent 1 standard error 
Hits

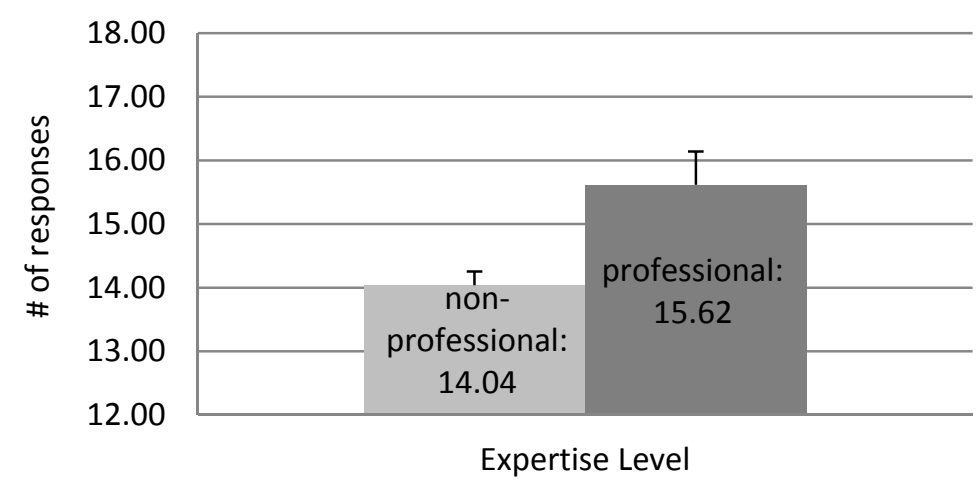

Figure 4. Difference between professional and non-professional drivers in Hits. Error bars represent 1 standard error

\section{Errors}

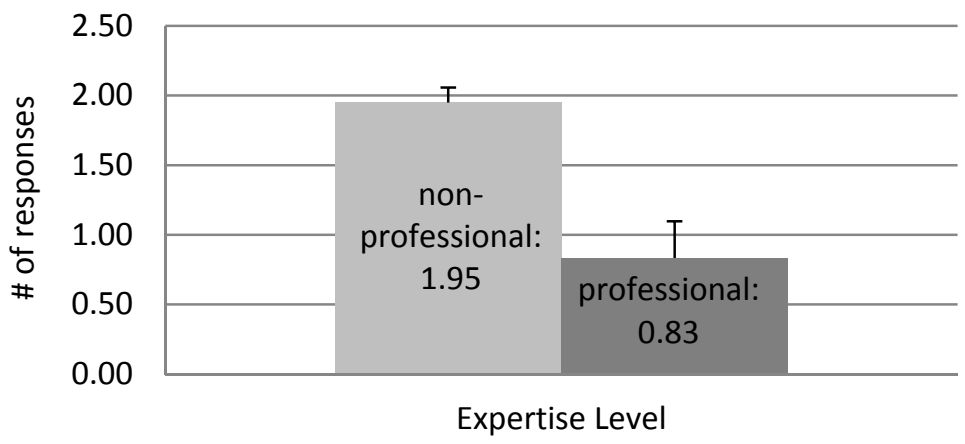

Figure 5. Difference between professional and non-professional drivers in Errors. Error bars represent 1 standard error

Next, separate multivariate analysis of variance (MANOVAs) were run for each expertise group to examine the association between age and gender (independent variables) and reaction time, hits, and errors (dependent variables).

In the professional MANOVA, the multivariate result was significant for gender $[\mathrm{F}(3,85)=$ 2.90, $\mathrm{p}<0.040$, Wilks' $\Lambda=0.907$, partial $\eta^{2}=0.093$ ]. The subsequent univariate analysis indicated that there was a significant difference between males and females exclusively for reaction time $[\mathrm{F}=8.64, \mathrm{df}=(1,87), \mathrm{p}=0.004]$. Specifically, female drivers were faster than male drivers. This result is the same as the one obtained in the overall MANOVA and depicted in Figure 2.

In the non-professional MANOVA, the multivariate result was significant for age $[\mathrm{F}(9,511)=$ 3.63, $\mathrm{p}<0.040$, Wilks' $\Lambda=0.860$, partial $\left.\eta^{2}=0.049\right]$. The univariate analysis indicated that there was a significant difference between age groups only for reaction time $[\mathrm{F}=8.40, \mathrm{df}=(3,212), \mathrm{p}$ $<0.001]$ and a post hoc analysis showed that the difference was specifically between groups 1 and 4 , where the youngest group was significantly faster than the oldest group $(\mathrm{p}<0.001)$. This result is shown in Figure 6. 


\section{Reaction Time}

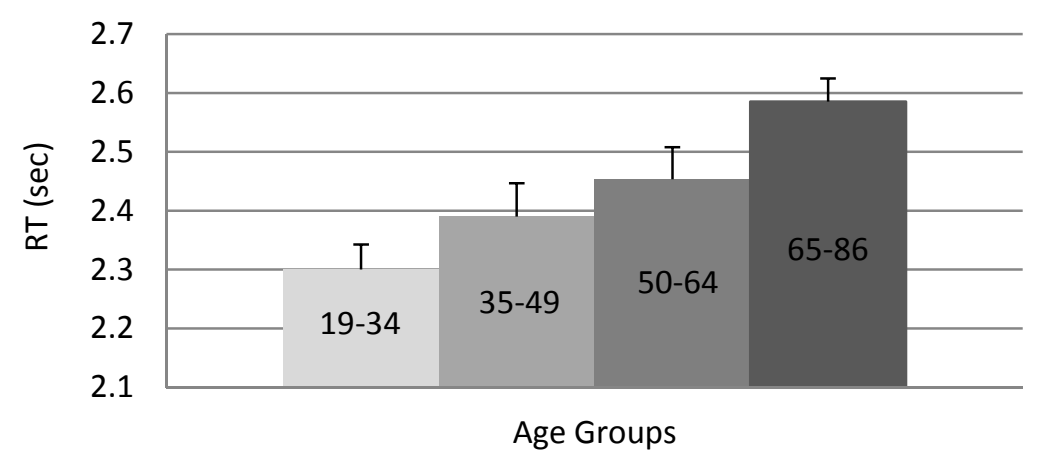

Figure 6. Difference across age groups in Reaction Time. Error bars represent 1 standard error

\section{CONCLUSION}

Results indicated that drivers' ability to perceive hazards, as indexed by the HPT, is mainly dependent on driving expertise. In the sample of the present study, the expected age effect seemed to disappear with training (as it was only apparent in the non-expert group). However, we would expect to see an age-related slowing effect emerge if a greater number of older drivers (i.e., over 65 years) were included in the sample. The difference observed between male and female expert drivers was possibly due to an imbalance in performance between groups. Although there were significantly more male experts, female expert performance was exceedingly superior. Our results are partially in accordance with previous studies conducted in other countries (e.g., Johnston \& Scialfa, 2016; Scialfa et al, 2012) and suggest that our adapted version can be employed in clinical settings where time pressure is much greater than in laboratory research.

In Brazil, driver's assessment is conducted on a frequent basis (every 5 years, on average). Thus, the development of a reliable tool to assess the ability to perceive hazardous traffic situations may be an invaluable resource, with the potential to impact the high mortality rates observed in the country. Additionally, the nature of driver assessment in Brazil allows for large-sample, population-based, longitudinal assessment of hazard perception and its relation to driver safety.

\section{REFERENCES}

Darby, P., Murray, W., \& Raeside, R. (2009). Applying online fleet driver assessment to help identify, target and reduce occupational road safety risks. Safety Science, 47, 436-442.

Goldman, L., \& Ausiello, D. (Eds.). (2009). Cecil Textbook of Medicine. Philadelphia: Saunders.

Global Status Report on Road Safety, 2015. http://www.who.int/violence_injury_prevention/road_safety_status/2015/report/en/

Horswill, M.S., \& McKenna, F.P. (2004). Driver's hazard perception ability: situation awareness on the road. In: S. Banbury \& S. Tremblay (Eds.), A cognitive approach to situation awareness: theory and application (155-175). Aldershot, UK: Ashgate. 
Johnston, K.A., \& Scialfa, C.T. (2016). Hazard perception in emergency medical service responders. Accident Analysis \& Prevention, 95, 91-96.

McKenna, F.P., \& Horswill M.S. (1999). Hazard perception and its relevance for driver licensing. Journal of the International Association of Traffic and Safety Sciences, 23, 26-41.

Quimby, A.R., Maycock, G., Carter, I.D., Dixon, R., \& Wall, J.G. (1986). Perceptual abilities of accident involved drivers (TRL Research Report 27). Crowthorne: Berkshire TRL Limited.

Scialfa, C.T., Borkenhagen, D., Lyon, J., Deschênes, M., Horswill, M., \& Wetton, M. (2012). The effects of driving experience on responses to static hazard perception test. Accident Analysis \& Prevention, 45, 547-553.

Scialfa, C.T., Deschênes, M.C., Ference, J.D., Boone, J., Horswill, M.S., \& Wetton, M. (2016). Hazard perception in older drivers. International Journal of Human Factors and Ergonomics, 1(3), 221-233.

Wells, P., Tong, S., Grayson, G., \& Jones, E. (2008). Cohort II: a study of learner and new driver: Volume 1 - Main Report. (Road Safety Research Report 81). London: Department for Transport. 